\title{
Smelly Encounters: An Olfactory Reading of Indian English Fiction by Women
}

\author{
Asha Choubey \\ MJP Rohilkhand University \\ *Corresponding Author: asha.choubey@gmail.com
}

Copyright (C) 2014 Horizon Research Publishing All rights reserved.

\begin{abstract}
George Orwell once described smell as the real secret of gender relations in the West: 'The female sex smells.' Gender connotation is writ large in almost every sociological/anthropological study of smell. Literature is also full of such references where women's sense of smell has been considered stronger than that of men's. Gaze being the masculine sense greater weightage has been given to it while smell has been deprecated as the feminine sense. Since smell has a deep cultural significance the literature of the Indian diaspora by women is replete with what may be termed 'olfactory analysis.' The smell of nostalgia, of memory and the past; the aroma of native food and all the native fragrances keep haunting; bringing much comfort to the aching heart. While Jhumpa Lahiri's characters are particularly nostalgic about the native food finding refuge in the gustatory, Chitra Banerjee Divakaruni dedicated the space of one novel to spices where her protagonist is the 'Mistress of Spices' herself; Radhika Jha's Smell reminds one of Patrick Suskind's Perfume. Replete with 'olfactory encounters', to borrow Janice Carlisle's expression, the novel is a buildungsroman of Leela Patel, the protagonist whose very being is apparently governed by her nose. I propose to read the olfactory representations in the novels of these women writers with a view to exploring the social, cultural and moral connotations of the olfactory/gustatory.
\end{abstract}

Keywords Olfactory, Gustatory, Indian English Fiction, Women Writing

\section{Introduction}

Fragrance is an essential component of who we are and what we know, conveying information in the forms of memory and emotion. [1]

Years ago, I had an Australian friend in Calcutta and I remember she loved to eat our curries but when my mother fried the lentils using ghee (purified butter) she used to shut her nostrils with her frock saying: "Chee! Chee! (sound to show disgust in Hindi) How foul a smell is this!" Ghee comes from cow milk which is considered sacred and we
Indians love its smell but the Australian girl had no such associations and completely disliked it. Smells have strong associative values; even a not-so-pleasant smell may be pleasing for some if it is associated with a pleasant memory. A friend of mine has an interesting story to tell about how smell helped her evade her mother's scolding as a naughty child. As a child she would keep a book open by her side when her brother and she would play cards in their study time. On smelling a baked-sweet smell both she and her brother would hide the cards and hold the open books in their hands pretending to be absorbed in reading it. Before the poor woman could barge in to see her children playing truant, it was the smell of her hair oil that would herald her entry.

\section{Cultural Fumes}

Before the sense of sight comes the sense of smell, yet smell is by far the most under-rated sense of perception. Constance Classen et al [2], while analyzing the course of its derogatory status, discuss the reason for its devaluation. They mainly see this as a result of revaluation of the senses in eighteen and nineteen century: "The philosophers and scientists [...] decided that, while sight was the pre-eminent sense of reason and civilization, smell was the sense of madness and savagery. In the course of human evolution, it was argued by Darwin, Freud and others, the sense of smell had been left behind and that of sight had taken priority" (1994: 30).

Smell is more cultural than sensual. The categories of the fragrant and foul are also not natural but cultural: what is deemed fragrant in some cultures is considered foul in some others. A Hindu would be shocked to learn that in Senegal and many other places in Africa, the smell of onion is classified as fragrant. Clearly, olfactory matters are not fixed but flexible.

In Andaman smell is granted a high status and the Andamanese calendar attaches much importance to aromas. The Andamanese people name the different periods of their year after the fragrant flowers that bloom at different times.

Smell is not only a sense of perception, it has been invested with deeper connotations across cultures in Asia. 
We Indians attach a lot of importance to this sense, it is associated not only with self but also with honour. 'Cutting off somebody's nose' means dishonouring the person; 'saving one's nose' means saving one's honour; 'a fat nose' means bloated ego and 'a matter of nose' means the matter of one's self-respect.

In India Gods are pleased when they are offered incense sticks. India has a long tradition of the olfactory just like the West. Sanskrit literature is full of references to perfumes and essences known as attar. Ancient Indian literature is replete with references to sweet-smelling flowers and to the practice of people wanting a lingering fragrance around them, of collecting flowers in a basket and keeping them in rooms; of bathing in water filled with aroma of the flowers; or of wearing flowers in their hair. To this day the practitioners of the ancient art of the olfactory keep dried flowers in cupboards, and clove tied in a small packet (potli), is kept inside clothes to give them a permanent fragrance. With the Mughal invasion came the Persian influence and the art of extracting oil to create perfume was acquired in India as well. Though these were basically individual oils, other kinds of attars may be composed by carefully blending these. It is believed that attar was first produced by Hakim Ibn Sena who used attars for medicinal purposes. Ratirahasya or The Secrets of Love written by Kukkoka in honour of Venudatta mentions Padmini ( a woman smelling like lotus) as the supreme type of woman. Drobnick refers to Wilber [3] who argues that South American Indians used perfumes to amplify vital human energy and fertility (2006: 229). Marriages in India are not sanctified without incense-sticks and sandalwood. This was a practice begun with Hinduism which came to be adopted by the followers of all religions in India.

\section{Fragrant Hinduism}

Spirituality and aroma have also had a long association across cultures. Hindu scriptures are full of references to perfumes, incense and scents used for worship. Clearly, olfaction has been an important sense in Hindu religion. The fact of India being a more spiritually/ religiously inclined society as compared to the West, which is a rationally inclined society cannot be ignored. In Saddharma-Pundarika there is an elaborate description of the five senses of perception and smell finds a place second to none. Mention is made of the bodhisattva's senses of perception: "Such is the power of his organ of smell. Yet it is not the divine organ he possesses, but (the natural one) prior to the perfect, divine faculty of smell" (Saddharma-Pundarika). In this description one can see no discrimination on the basis of gender. Men and women smell equally, in fact, men's power of smell is even greater than that of women because Bodhisattva is male. In the Srimad Devi Bhagawatam [4] while elaborating on the rules of diksha (initiation) one finds:

Worship the whole body of the Devî with scents and flowers. Next offer to the Devî the sweet scent of Kalâguru mixed with camphor and the Kâs'mîri sandalpaste mixed with Kastûrî and various nice scented flowers, for example, the Kunda flowers, etc. Then offer the Dhûpa prepared from Aguru, Guggula, Us'îra, sandalpaste, sugar, and honey and know that the Dhupa is very pleasing to the Devî. Next offer various lights and offerings of fruits, vegetables and fooding. Be particular to sprinkle everything with the water of the Kosâ, thus purifying, before it is offered to the Devî. Then complete the Anga Pujâ, and the Avvarana-Pûjâ of the Devî, then perform the duty of Vais'vadeva. On the right side of the Devî erect an altar (sthandila) six feet square and install Agni (Fire) there. Invoke there the Deity, thinking of Her Form and worship Her with scents and flowers.

Incense and anointment with sandal paste and other scents find prominent place on the list of fourteen articles to be offered to please gods: (6) anointment with sandalpaste and other scents (Anulepana), (7) incense (Dhûpa), (9) offerings of food (Naivedya), (10) Betels (Tambûl), (14) garlands, scents" (Bagawahtam. IX: XVI). Out of the fourteen offerings that appease gods one can see that five items pertain to the olfactory, as food itself is savour combined with flavor.

In the description of Santanu and Satyavati's marriage one clearly finds that it is smell that attracts the King to Satyavati and leads to their marriage:

At last he came to a spot on the banks of the Yamunâ the chief of the rivers, where a very beautiful girl, calm and quiet and with feminine gestures and posture amorous, lovely but ill-clad, was sitting; and he found out that the above beautiful smell [emphasis mine] was coming out of her body. The form of the lady was extremely beautiful; the smell was very wonderful, and captivating the hearts of all; her age then entered to youth and she was very auspicious [5].

It may be mentioned here that in India, especially in Hindu tradition, reference to foul smell is absent. This may be attributed to the fact that Hindu scriptures associate all the five senses including smell with the divine. Hindus have this knack of associating all useful things with God e.g., rivers, flora, fauna etc. In the medieval times, however, due to Persian influence, scents became associated with black magic and also elimination of bad smell became a concern.

\section{Feminization of Smell}

"While other spirits glide on the wings of music, Mine, O my love! floats upon your perfume" [6]

Aristotle recognized smell as an emotional sense and later Rousseau called it the "sense of imagination" thus, pointing at the femininity of the olfactory sense. George Orwell [7] once described smell as the real secret of gender relations in 
the West: "The female sex smells" (1937: 159). Gender connotation is writ large in almost every sociological/anthropological study of smell. Literature is also full of such references where women's sense of smell has been considered stronger than that of men's. Gaze being the masculine sense greater weightage has been given to it while smell has been deprecated as the feminine sense. Feminization of the olfactory began in large measures in the nineteenth century. This began with the deprecation of this sense; all things deprecated were considered to be associated with each other and women were as devalued as was the passive sense of smell. All of a sudden the sense of perception which was thought to be the closest to the deities, went out of favour. The sanctity of odours and its therapeutic powers all became a story of the past while the present reality associated smell with women, savages and animals. Analyzing the reasons for smell going out of favour, Classen et al [8] write:

Smell, in turn, was now considered the sense of intuition and sentiment, of home-making and seduction, all of which were associated with women. It was maps, microscopes and money on the one hand, and pot-pourris, pabulum and perfume on the other. Significantly, however, smell was also the sense of 'savages' and animals, two categories of beings who, like women, were deprecated and exploited by contemporary Western culture (84).

Classen et al attribute this olfactory deprecation of women to their association with the moon which, in turn, was associated with corruption. It is commonly accepted in the West that women are the perfumed sex. Hence, in postmodern times the only basic purpose of fragrance is to enhance the desirability of the sexes. Chastity however, still remains associated with fragrance. The Spanish word for whore, 'puta' is derived from the Latin for putrid, so is 'putain' in French. While wives and mothers are surrounded of respectable perfume, seductresses have heavy \& spicy smell. In India, unlike the Americas, men too love to wear perfume. A. H. Verrill [9] writes about the American man:

Though his women use more perfumes than any other race on earth, and although the inhabitants of the United States spend more money on perfumes and cosmetics than on education, the use of perfume in any form is abhorrent to the American male. In vain have perfumers tried to introduce 'manly' scents such as leather, scotch, hay, clover, and salt marsh, etc. Not one has succeeded. And the men of American blood remain firm in their determination not to use perfumes (97).

The truth of Verrill's statement is not much supported by facts though. In India as in other Asian countries men love to use fragrant aftershave lotions as well as deodorants and perfumes. In this regard at least, Indians have no gender bias.

In Andaman again the olfactory is associated with women very closely but not in its deprecated form. The time of a girl's first menstruation is referred to as her 'blossoming time'; she is given the name of the flower that blooms at that time till she bears her 'first fruit,' her first child. Cain [10] and Engen [11] conducted much research on gender as it affects odour perception; all of which remained inconclusive though. However, my intention here is not to go into the anthropological or socio-religio-cultural significance of the sense of smell. I would rather trace how well this sense has found representation in literature, Indian English fiction to be precise.

\section{Literary Gusts}

In the post-modern world, with visual media gaining more and more importance, smell is gradually receding into the background. Computers do not have any room for the olfactory. However, the fragrance industry, the toothpaste industry and the soap industry still manage to keep the traces of the pre-modern relevance of smell alive; and it is not unusual to come across advertisements flaunting the value of smell to attract men and women. Especially notable is the fact that gender is a focal point in these advertisements. In contemporary times, however, literature has realized the power of the olfactory and since the eighties smell has become the central point of many a poem and fiction piece. Patrick Suskind's [12] The Perfume is a powerful example in this regard. The story of a psychopath perfumer makes for a powerful case of the denigration of olfaction and by default it strengthens the nineteenth-century view. The protagonist is so obsessed with scent that he ends up killing maidens in order to sniff up their sweet fragrance. In the end, through his de-scenting of maidens he gets invested with such an appealing perfume that a frenzied crowd tears him to pieces and eats him up.

The onset of the avant-garde group of writers and poets had a positive turn for the olfactory. Literature abounds with references to smell. Smell has been convincingly used to describe mourning, nostalgia and yearning, love, spring, horror, ugliness, death, infancy and many other emotions and phenomena.

\section{Indian Context}

Since smell has a deep cultural significance the literature of the Indian diaspora by women is full of what may be termed 'olfactory analysis.' The smell of nostalgia, of memory and the past; the aroma of native food and all the native fragrances keep haunting; bringing much comfort to the aching heart. While Chitra Banerjee Divakaruni [13] dedicated the space of one novel to spices where her protagonist is the 'Mistress of Spices' herself; Radhika Jha's [14] Smell reminds one of Patrick Suskind's Perfume. Replete with 'olfactory encounters' to borrow Janice Carlisle's expression, the novel is a buildungsroman of Leela Patel, the protagonist whose very being is apparently governed by her nose. I propose to read the olfactory 
representations in the novels of these women writers with a view to exploring the social, cultural and moral connotations of the olfactory/gustatory.

\section{Moral Smells}

A sixteenth-century allegory tells the story of an angel who has no objection to the smell of an honest dung-collector's laden cart, but who stops up his nose at a perfumed courtesan. In Radhika Jha's novel Smell one can see the olfactory as the leit motif. Smell presents an olfactory narration of a pure, innocent girl with a strong olfactory sense who starts having strange 'smelly encounters' when she becomes morally degenerate. Jha's narrative makes a powerful statement of the olfactory. The protagonist Leela Patel has an acute case of phantosmia (a syndrome described as olfactory hallucination). Since her childhood Leela's world is dominated by the aroma of food and spices, which become her medium of communication with a country (India) which is hers but which she has never been to. She experiences the smell of her country, that she knows and associates with home, infused with French aromas e.g., "the smell of fresh baguette would fight its way into the Madras epicerie to do battle with the prickly smell of pickles and masalas (spices) ... it would pause, some of its strength diminished by the pungent foreign odours" (3).

Leela is one person for whom all the other senses are dominated by her nose. Even in the dark she could take to a place if only it smelt fresh. When in pain she has the tendency to recall pleasurable smells which soothe her ache. While washing the dirty dishes in her aunt's kitchen, she takes refuge in some old olfactory memory. Leela's world is a 'nosy world' if one may say so. Airs and fumes impact her mind more than imagery does. Her olfactory memory portends her future in Paris at the instance of her entering into her uncle's home when, "Almost immediately I could smell it - that smell of oil, pickle and spices, which is the hallmark of the Indian home" (12). This native smell seems quite out of place, hence unwelcome. Leela takes immediate dislike to her Aunt Latha and she starts smelling an "ugly death smell" (31) in her kitchen. Ironically, it is later this same aunt who, while training her in the use of spices, says: "...listen to the smell, it will tell you things" (31). This merger of the smell and sound is what makes smell more potent and overpowering. When smells begin to sound, they acquire character. This 'mixing' of the senses has been accepted as a reality by neurologists and a report published in Medical News Today [15], affirms this merger: "Surprising as it may seem, there are people who can smell sounds, see smells or hear colors. Actually, all of us, at some point in our lives, have had this skill".

So obsessed with smell is Leela that she tells her friend Clothilde alias Lotti: "The smells haunt me, they talk to me-telling me about their loves, their hates, their need of company and warmth, their fear of dying. I cannot rid their feelings from my brain" (60).
A migration from Kenya to Paris augments Leela's sense of smell drastically. Having been forced by her penury to become an au pair with the Balenie family, Leela not only becomes Lily for Ms. Balenie's convenience, but also for the convenience of Mr. Bruno Balenie, she becomes his mistress. A docile, simple girl when she is forced to allow people to use her body, Leela loses respect for herself. Her body begins to smell, then, of sin. Bruno, like all men before him, uses Leela for his pleasure and discards her once he has taken his fill of her and discovers Leela's smell. When she realizes her real position with Bruno she reflects : "He was a liar. And he had infected me with a terrible smell... After that, the smell haunted me, surfacing when I least expected " (117).

Leela's journey may be read parallel to Grenouille, the weird protagonist of Perfume who is rejected by others because of his lack of personal smell. He goes to great extents to steal smell from others' bodies while Lily, alias Leela, would do anything to divest herself of this smell which seems to give away her secrets. Wanting badly to break this "smelly cocoon" (125), for a while Leela starts to give a second thought to Lotti's suggestions of going back to Aunt Latha: "If I went back to their world - the world of my aunt and uncle and the Ramdhunes, my smell could be hidden behind the spices and the heavy fragrant oils of their food" (124). This also clearly brings out the metaphoric dimensions of smell, staying with the family Leela would not be suspected of having immoral liaisons with lusty men; behind the respectability of a family her sinfulness would find a refuge. Sacked from many a job she finally becomes a prostitute and realizes that her body has begun to stink : "My smell surrounds me like a shroud, rotten and sweetly fermenting....The dead vegetable odours get more and more pronounced as I breathe" (266).

After wandering through many smelly encounters, Leela finally meets Philippe who she really loves. In Philippe she discovers a protective comforting smell that she looks for everywhere: "You see, after you leave, your smell keeps me company, almost as if you were still there. It comforts me" (184). Leela beats the French at their own grounds, telling them some undiscovered facts about smell: "What do you mean? -the idea of smell? A smell is not an idea. It's real. Everything has a smell, and the smell changes all the time depending on how it's treated. A smell is a world... it is memory too" (199).

It is however noticeable that Leela smells bad only when she is rubbed the wrong way. Her journey which starts from the kitchen smells, culminates in body odors of all kinds giving out the secrets of her straying away. It may be mentioned here that Leela's smelliness has more to do with morality than with gender. It is her fall from the accepted norms of society that results in her smelling body. More interesting would be the fact that in this immoral sense only women are seen as smelly as if men never fall. Clearly, the notions of virtue and vice work only in connection with women. Indians are more obsessed with the idea of virtue in woman. For women it is important to be virtuous because that is normal for them. Promiscuity may be normal for men, 
but completely abnormal for women hence, those that degenerate start oozing foul smell. Again, this discussion on normal vs. smelly women may be linked with disability. Disability is defined as abnormality hence, foul smell being not normal is a disability. Since only women (immoral?) smell, they are disabled while men howsoever much lecherous do not smell and they are full-bodied normal and healthy. But, more on this some other time.

\section{Therapeutics of Smell: Mistress of Spices}

Incense finds an important place in magical ceremonies in all of Asia. A particular kind of incense in China is said to have the power of calling up human spirits. There is also some mention of Jiki-ko-ki or incense eating goblins in Japanese Buddhism. In India, the traditional method of greeting in Vedic time was to smell someone's head. Thus the Vedas speak of the satisfaction fathers take in smelling the heads of their children after returning from an absence. This act was as meaningful and affectionate as a kiss or hug would be in the West. Classen et al [16] write a section on "Healing by Smell" in their book mentioning the cultural healing practices of the Romans:

The ancient custom of applying perfumes to the head and chest, consequently, was not simply an aesthetic practice but also a means of promoting well-being (40).

Olfactory memory plays an important part in the life of diasporas. In an alien world, in the absence of all familiar associations, memory of known smells relieves the pain of nostalgia. The medicinal property of smells becomes the very theme of Chitra Banerjee Divakaruni's Mistress of Spices. Moving a step farther from Jha, Banerjee writes the story of a wonder woman who not only shares many of the immigrants' pains but also successfully heals many of them through her expertise in handling spices. Banerjee touches hitherto unexplored horizons in the history of olfactory literature with her Mistress of Spices. Mistress is a giant leap in the genre of magic realism. The narrative is divided into chapters that are named after Indian herbs and spices - starting from tilo that is the protagonist as well as sesame to the last but one chapter which is named Sesame. Tilottama, the spice woman, treats the painful hearts in diaspora by using the medicinal properties of Indian spices. Since all this pain is bred from alienation, the familiar smell of spices provides proper remedy. Jagjit's innocent heart, Geeta's rebellious spirit, Haroun's fearful soul, Ahuja's wife's tortured existence, Lalita's traumatic nights - all find their manna in Indian spices administered by Tilottama.

Tilottama, the protagonist herself, takes her name from a spice - tilo (sesame), and she knows exactly what the longing hearts in diaspora, aching for a slice of familiarity, yearn for:
Emerald green burfis 1, rossogollas 2 white as dawn and, made from lentil flower, laddus 3 ... when one has chewed amlaki [Phyllanthus amarus] to freshen the breath (5).

Tilo has peppercorn, kalo jire, neem, red chili, lotus root to heal the immigrant pain as she declares: "I, Tilo architect of the immigrant dream. O Haroun, I sent up a plea for you into the crackling air you left behind. Sandalwood keep safe the brightness in his eye" (29). Tilo plays with the aroma of spices, bringing about some solace to Jagjit's oppressed life: "Crushed clove and caradamom, Jagjit, to make your breath fragrant. Cardamom, which I, your teacher will scatter tonight on the wind for you (41-42). Tilo has many such prescriptions ready on her tips: "You shall be called Aparajita after flower whose juice, smeared on eyelids, leads one to victory" (43); "Oceans of oil and honey to bathe in, sparkling palaces of rock-sugar" (51).

In times when Aromatherapy has come to exist as a scientific and proven method of healing, it is quite easy to accept the reality of what Tilo does to her patients. Much in the fashion of the French perfumier Rene Gattefosse, Tilo's incantations to the spices work wonders more often than not. Banerjee builds the narration on the olfactory and adds a new dimension to smell.

Banerjee's book seems over-sprinkled with the aroma of spices, flavors of food and fragrance of flowers throughout. Jha, however, deals mostly in imagined smells and also artificial de-odorants. Her protagonist has a nose for different spices and food aromas but the smell that dominates is the smell of her body which is sometimes real and sometimes hallucinative. Whatever be their calling, and position in society, both Leela and Tilottama are in the truest sense of the term 'smelly women' inasmuch as both of them smell, both deal in smells, both have a heightened olfactory sense and both influence others' life by using their smells. It is ironic then, that both these women meet their undoing in smells only. Tilo, while trying to remedy the American's ache, becomes a victim of his love and is finally compelled to leave her empire of spices. She loses all her magical powers and becomes on ordinary woman divested of her kingdom of smells. Leela, who could work wonders in the kitchen with aromas, finally becomes overpowered by her bodily smell and runs from Bruno to Phillipe to Marc till finally she meets the puppeteer Laure with whom she finds herself sharing all her secrets. Laure shows her the real Leela: "You don't smell. You have never smelt," he says at last. "You want to think you smell because that way... it will become impossible for anyone to hurt you, because you have already rejected yourself" (288).

Immigrants' ache of separation and longing finds relief in smell/food from the native land. Tilottama finds relief in the smells of spices; she set out to control the spices to use their pungent aroma to help immigrants, instead she comes under

1 Diamond shaped sweetmeat made with thickened milk.

2 A kind of sweetmeat made by frying thickened milk-balls in oil and dipping them in sugar syrup.

3 A kind of ball-shaped sweet meat, made with gram-flour. 
the control of these spices herself. Leela and Tilottama both are one in terms of their olfactory capabilities and talents.

\section{Conclusion}

In the hands of Indian women writers, thus, the olfactory takes newer dimensions, to be matched by no other sense. If Leela is a 'wizard with spices', Banerjee paints a mistress of spices in the person of Tilottama. Jha, and Banerjee have created truly olfactory/gustatory specimens of women. Banerjee creates a parallel world of native familiar smells for the aching heart in diaspora. These writers bring in what may be termed a renaissance of the olfactory which could well revolutionize the fiction of sensuousness.

\section{Endnotes}

1) This phenomenon, called "synaesthesia" - from the Greek "syn" (with) and "aisthesis" (sensation) - consists of the pairing of two bodily senses by which the perception of a determined stimulus activates a different subjective perception with no external stimulus (in science, the evoker stimulus is called inducer and the additional experience concurrent). Further the report reiterates: "Then, there are people for whom time units evoke colors .... It is also common for a synaesthete to see colors when listening to words, sounds in general or music notes (people who can see music, for instance). There are also cases, although fewer, where people can see colors in flavors, others perceive flavors or experience touch sensations when listening to different sounds, some link flavors to touch sensations, etc."

2) In Vedanta philosophy Maya has been described as illusion. Something which is neither real (Sat) nor unreal (Asat) nor partly real and partly unreal (Sadasat).

\section{REFERENCES}

[1] Kathleen Cerrer, "Making sense of your scent," The Uniter, 4 October 2010. Online available from http://uniter.ca/view/49 30

[2] Constance Classen, David Howes and Anthony Synnott, Aroma: The Cultural History of Smell, Routledge, New York, 1994.

[3] Jim Drobnick, The Smell Culture Reader. Berg, London, 2006.

[4] Bhagawatam. bk. IX. Ch. XXVI. Online available from http://www.sacred-texts.com/hin/db/bk09ch26.htm

[5] Bhagawatam. bk. II Ch. V Online available from http://www.sacred-texts.com/hin/db/bk02ch05.htm

[6] Charles Baudelaire, "La Chevelure/Head of Hair", L.9-10. trans. William Aggeler, The Flowers of Evil, Academy Library Guild, Fresno, CA, 1954.

[7] George Orwell, The Road to Wigan Pier, Victor Gollancz, London, 1937.

[8] Constance Classen, David Howes and Anthony Synnott, Aroma: The Cultural History of Smell, Routledge, New York, 1994.

[9] A. H. Verrill, Perfumes and Spices, Boston, L. C. Page, 1940.

[10] W. S. Cain, "Odor identification by males and females: predictions vs performance." Chemical Senses, 7, 1982.

[11] Trygg Engen, The perception of odors. Academic Press, New York, 1982.

[12] Patrick Suskind, The Perfume. 1985. Trans. John E. Woods, Penguin Books, UK, 1987.

[13] Chitra Banerjee Divakaruni, Mistress of Spices, Anchor Books, New York, 1998. (All subsequent references in parentheses are from this edition).

[14] Jha, Radhika. Smell. New Delhi: Penguin Books. 1999. (All subsequent references in parentheses are from this edition).

[15] "Some People Can Hear A Color Or Smell A Sound" 26 Nov. 2007. Online available from http://www.medicalnewstoday.c om/releases/92698.php

[16] Constance Classen, Worlds of Sense: Exploring the Senses in History and Across Cultures, Routledge, London, 1993. 